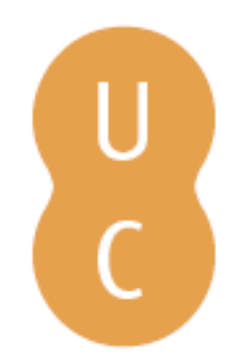

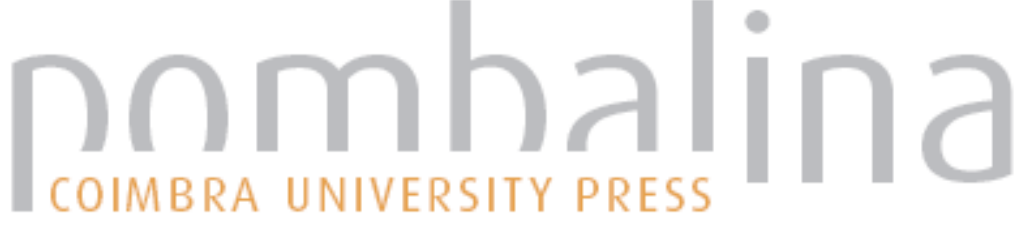

\section{Formação de advérbios em -mente}
Autor(es):
Rio-Torto, Graça

Publicado por: Imprensa da Universidade de Coimbra

URL

persistente:

URI:http://hdl.handle.net/10316.2/38918

DOI:

DOI:http://dx.doi.org/10.14195/978-989-26-0864-8_6

Accessed : $\quad$ 26-Apr-2023 13:49:36

A navegação consulta e descarregamento dos títulos inseridos nas Bibliotecas Digitais UC Digitalis, UC Pombalina e UC Impactum, pressupõem a aceitação plena e sem reservas dos Termos e Condições de Uso destas Bibliotecas Digitais, disponíveis em https://digitalis.uc.pt/pt-pt/termos.

Conforme exposto nos referidos Termos e Condições de Uso, o descarregamento de títulos de acesso restrito requer uma licença válida de autorização devendo o utilizador aceder ao(s) documento(s) a partir de um endereço de IP da instituição detentora da supramencionada licença.

Ao utilizador é apenas permitido o descarregamento para uso pessoal, pelo que o emprego do(s) título(s) descarregado(s) para outro fim, designadamente comercial, carece de autorização do respetivo autor ou editor da obra.

Na medida em que todas as obras da UC Digitalis se encontram protegidas pelo Código do Direito de Autor e Direitos Conexos e demais legislação aplicável, toda a cópia, parcial ou total, deste documento, nos casos em que é legalmente admitida, deverá conter ou fazer-se acompanhar por este aviso. 


\section{GRAMÁTICA \\ DERIVACIONAL \\ DO PORTUGUÊS}

GRAÇA RIO-TORTO

ALEXANDRA SOARES RODRIGUES

ISABEL PEREIRA

RUI PEREIRA

SÍLVIA RIBEIRO

2. ${ }^{a}$ EDIÇÃO

IMPRENSA DA UNIVERSIDADE DE COIMBRA COIMBRA UNIVERSITY PRESS 


\section{CAPÍTULO 6. FORMAÇÃO DEADVÉBIOS EM - M E N TE}

Graça Rio-Torto

\subsection{Entre a composição e a derivação}

O adverbializador -mente tem origem no nome latino MENS, MENTIS, e combina-se dominantemente com bases adjetivais, sejam simples (1) ou derivadas (2), e com alguns numerais multiplicativos, quando usados com valor intensivo, como em duplamente, triplamente.

(1)bases simples: alegremente, amplamente, capazmente, certamente, corretamente, diretamente, facilmente, felizmente, habilmente, imensamente, juntamente, justamente, ligeiramente, mormente, paralelamente, plenamente, precisamente, propriamente, sabiamente, simplesmente

(2)bases derivadas: ameaçadoramente, antecipadamente, basicamente, confortavelmente, devidamente, discutivelmente, essencialmente, bipoteticamente, inconclusivamente, infatigavelmente, justificadamente, saborosamente, terminantemente

A forma da base adjetival selecionada é a feminina, quando o adjetivo admite marcação formal de género (boamente, chãmente, claramente, cristãmente, genuinamente, raramente, sãmente), dando 
assim continuidade a um fenómeno de concordância de género entre adjetivo e o primitivo nome latino.

A natureza do processo que envolve adjunção de -mente aproxima-se em alguns aspetos da derivação e em outros da composição (Basílio 1988, Gonçalves 2011).

Os argumentos que têm sido invocados em favor da semelhança de procedimentos com a composição são essencialmente os dois seguintes:

(i) o facto de -mente se combinar com palavras que exibem marcas ([+feminino]) de flexão. A composição, nomeadamente a sintagmática e a morfossintática, opera com palavras, e mais ainda com palavras portadoras de marcas flexionais (alta-fidelidade, alto-relevo; belas-artes, belo-canto; novo-mundo, nova-rica; parvo-alegre, parva-alegre; pato bravo, pata-choca; santa-sé, santo-graal). A derivação opera com temas e com radicais, por inerência não flexionados (cf. cap. 1). A intervenção da sintaxe no interior do produto é, pois, determinante na delimitação da composição (cf. cap. 8) ou dos processos mais próximos desta, como a adverbialização em -mente ou a formação de z-avaliativos (cf. cap. 5), face à afixação. Para uma visão do contínuo entre estas modalidades de formação de palavras, veja-se cap. 7 e 8 .

(ii) as bases a que -mente se acopla não alteram a sua identidade fónica, pois as vogais tónicas destas não sofrem no PE o processo de elevação e recuo típico do vocalismo pré-tónico: agilmente, celeremente, pobremente, mantêm as vogais $<\mathrm{a}>$, $<\mathrm{e}\rangle \mathrm{e}<\mathrm{o}\rangle$ baixas, o mesmo não acontecendo em contexto derivacional, no PE (agilidade, celeridade, pobreza). A não aplicação da regra do vocalismo átono é, pois, comum a compostos (agroturismo, termodinâmica, rodoviária, em que as vogais $\langle\mathrm{a}\rangle,\langle\mathrm{e}\rangle$ e $\langle\mathrm{o}\rangle$ se mantêm baixas) e a advérbios em -mente (facilmente, rapidamente, certamente, fortemente). 
Por outro lado, a paradigmatização e a significativa representatividade do processo de adjunção de -mente a bases adjetivais aproximam o mecanismo de produção de advérbios da derivação. A perceção da grande produtividade deste processo, que aliás faz com que muitos dicionários não registem de forma sistemática os advérbios em -mente, leva Jerónimo Soares Barbosa, na sua Grammatica philosophica da lingua portugueza (1822: 340), a considerar que "A formação desta sorte de adverbios [que denomina de advérbios de qualidade] he tão regular que não soffre excepção alguma». Ora, se por um lado a formação de advérbios em -mente é um mecanismo claramente paradigmatizado e estabilizado na língua e de grande produtividade, está longe de ser verdade que se trata de um processo que não sofre exceção alguma. A análise das possibilidades e das impossibilidades combinatórias, e da natureza dos condicionalismos que as comandam, procura esclarecer esta questão.

Estando, pois, na interface entre composição e derivação, na génese deste mecanismo de adverbialização encontra-se um processo de gramaticalização.

Na secção 6.2. deste cap. descrevem-se algumas das mais significativas restrições categoriais, semânticas e morfológicas da adjunção de -mente, e na secção 6.3. analisam-se as condições morfológicas e semânticas de combinatória, e respetivas situações de exceção.

\subsection{Restrições categoriais, semânticas e morfológicas}

\subsubsection{Restrições categoriais}

$\mathrm{O}$ adverbializador -mente combina-se com bases adjetivais. A agramaticalidade das combinatórias (3-10) com advérbios, conjunções, nomes, numerais, pronomes, verbos, preposições comprova esta realidade. 


\begin{tabular}{|c|c|c|}
\hline (3) Nomes & (6) Pronomes & (9) Verbos \\
\hline alegria: *alegriamente & ela: *elamente & dançar: *dançarmente \\
\hline jacaré: *jacaremente & esta: *estamente & ler: *lermente \\
\hline meloa: "meloamente & minha: *minbamente & \\
\hline (4) Preposições & (7) Conjunções & (10) Numerais fracionários: \\
\hline após: *aposmente & mas: *masmente & meio: *meiamente \\
\hline dentro: *dentromente & portanto: "portantomente & terço: *terçamente \\
\hline (5) Numerais ordinais ${ }^{65}$ : & (8) Numerais cardinais: & \\
\hline segundo: *segundamente & dois: *doismente & \\
\hline terceiro: "terceiramente & dez: *dezmente & \\
\hline
\end{tabular}

Com numerais multiplicativos, muitas vezes usados como adjetivos (triplo, quádruplo), a adverbialização é possível.

(11) triplamente, quadruplamente

Uma vez que -mente se junta à forma feminina da base, é natural que não se combine com palavras invariáveis, como preposições, conjunções, advérbios, e também com palavras não variáveis em género, como os verbos. Alguns pronomes pessoais, apesar de variáveis em género, também não são compatíveis com -mente, por razões semânticas, pois não denotam propriedades.

Não obstante, em registos estético-literários, sempre mais permissivos a criações mais heterodoxas, é possível encontrar advérbios em -mente que têm por base nomes próprios (cf. 12, de. Camilo Castelo Branco), e outras classes de base não selecionáveis pela língua não literária. Filinto Elísio (13), Mia Couto (14) usam este recurso, e Guimarães Rosa (15) é amplamente conhecido pela sua grande prolificidade neste domínio.

(12) ela resistiu lucreciamente

65 Tenha-se em conta que primeiramente não denota 'à maneira do primeiro', mas tem sentido temporal de 'em primeiro lugar'. 
(13) mulhermente

(14) bastantemente [carregadíssimos]

(15) antesmente, aposmente, coraçãomente, desdemente, depoismente, duasmente, maismente, minhamente, muitamente, quasemente, talmente, tãomente, todasmente, mil-vezes-mente, com-fomemente

No caso (12), em que o advérbio equivale a 'à maneira virtuosa de Lucrécia', o nome próprio Lucrécia é usado como um predicador, denotando as propriedades estereotipicamente associadas à personalidade em causa.

Também J. Saramago usa festivalmente ( $O$ ano da morte de Ricardo Reis. Lisboa. Caminho, 16ed.: 333) em "deixa-se ir na corrente dos curiosos que festivalmente acorrem ao teatro de guerra».

Estes exemplos ilustram a derrogação que os escritores fazem das imposições categoriais da língua comum, combinando -mente com todas as classes de palavras acima consideradas incompatíveis com adverbialização.

Também em situações ritualizadas, como "saudai-vos irmãmente', na base do advérbio está o predicado 'fraterno, como irmãos', e não o nome que denota uma relação de parentesco.

Uma classe de palavras com as quais -mente também não se combina é a dos particípios, pois estes são formas verbais, usadas prototipicamente nos tempos compostos, com o auxiliar TER ( $\mathrm{x}$ tem atendido). Como em muitos casos a língua possui adjetivos homólogos das formas participais (atendido vs. atento), afirma-se erroneamente que os advérbios têm por base estas. Mas o estudo das formas adjetivais irregulares dos chamados verbos "abundantes" mostra que na base do advérbio está o adjetivo (atentamente), e não o particípio (cf. 6.3.2.1. deste cap.).

\subsubsection{Restrições semânticas}

São várias as subclasses morfossemânticas de adjetivos que não admitem adverbialização. 
Uma vez que o advérbio significa "de modo x" (cf. à toa e atoamente), "à maneira de X" (renitentemente), é de esperar que os adjetivos selecionados sejam capazes de funcionar como predicadores de actantes verbais. Assim se explica a não combinação com adjetivos estativos ("enfermamente, *solteiramente) e com alguns dos classificatórios denominais (*agrariamente, *navalmente) que, quando usados em sentido literal, não admitem adverbialização.

Como a informação semântica se sobrepõe à natureza morfologicamente complexa ou não da base, vamos privilegiar aquela em detrimento desta, incluindo portanto nas classes semânticas bases simples (calvamente feliz, sexy; viuvamente "sua tão viuvamente nova-do-Carmo, de cama, no quarto que foi de ambos» Óscar Kellner Neto, A encrenca, https://books.google.pt/books) e bases derivadas.

\subsubsection{Adjetivos étnicos, pátrios, gentílicos}

Pela sua semântica, os adjetivos gentílicos/pátrios, no seu sentido literal, não admitem adverbialização. A maior parte destes adjetivos tem origem denominal, e por isso se elencam aqui (16-23) pela ordem alfabética dos sufixos de que são portadores.

(16) -an-: *africanamente, *angolanamente, *cubanamente, *italianamente

(17) -ã (o): *afegãmente, *alemãmente, *catalãmente

(18) -ens-: *guineensemente, *vianensemente, *viseensemente

(19) -ês: *chinesmente, *escocesmente, *francesmente, *mirandesmente 66

${ }^{66}$ A configuração -ês (e não -esa) é uma reminiscência do facto de no português antigo o sufixo - $\hat{e}$ ser comum de dois géneros. 
(20) -in-: *londrinamente, *marroquinamente, *tunisinamente

(21) -it-: *israelitamente, *moscovitamente

(22) -ol: *espanholamente

(23) -ot-: *cipriotamente

Os advérbios burguesmente e cortesmente já não têm, como aliás as respetivas bases adjetivais (burguês, cortês), um sentido literal ('do burgo, da corte'), pelo que são os sentidos lexicalizados ('da burguesia, acomodado na vida' e 'urbano, que age com urbanidade') que são selecionados por -mente.

Também portuguesmente ou brasileiramente tomam por base os sentidos estereotípicos associados aos adjetivos português e brasileiro, não os sentidos literais de "nascido em, oriundo de Portugal/ Brasil". Outros adjetivos deste tipo, usados nas mesmas condições, são admissíveis: "portuensemente falando", isto é, falando 'à moda do Porto/de um portuense'.

\subsubsection{Adjetivos com sufixos avaliativos}

Os adjetivos deadjetivais, quando portadores de sufixos avaliativos, não admitem adverbialização em -mente.

(24) -on-: *bonitonamente, *grandonamente, *grosseironamente, *molengonamente

(25) -inh-: "gordinhamente, *grandinhamente, *magrinhamente, *tolinhamente

(26) -it-: *granditamente, *magritamente, *pequenitamente, *parvitamente

(27) -ot(a): *atrevidotamente, *mauzotamente, *pequenotamente, *velhotamente 
Já o advérbio finoriamente, não obstante ter por base um adjetivo avaliativo formado com um sufixo expressivo e de menor representatividade na língua, está amplamente atestado.

\subsubsection{Adjetivos no grau comparativo}

A adjunção de -mente não é possível a adjetivos na forma e com a significação comparativa, mesmo quando se trata de formulações irregulares e, por isso, há muito fixadas na língua: *maiormente, *melhormente, *menormente, *piormente.

Este aspeto é particularmente impressivo porque a adverbialização é possível quando a base se encontra no superlativo (cf. 6.3 deste cap.).

\subsubsection{Restrições morfológicas}

São essencialmente de natureza semântica as condições que determinam a (não) combinação de -mente com bases adjetivais. Por isso em português coexistem bases sufixadas portadoras de um sufixo que rejeitam a adverbialização (*pedresmente) e outras bem formadas (cortesmente) em que o mesmo está presente (cf. 6.3. deste cap.).

\subsubsection{Bases adjetivais sufixadas}

Não se combinam com -mente os adjetivos cujas bases sufixadas nominais denotam, no seu sentido literal, algumas realidades tangíveis ("pedregosamente, "postalmente), sendo aceites as que têm significado temporal (anualmente, diariamente) ou mais abstrato (ambiciosamente, historicamente, naturalmente, ordinariamente). 
O adverbializador não se combina com os derivados deverbais sufixados em - vel quando portadores de sentido de potencialidade passiva:

(28) -vel: *aproveitavelmente, *desmascaravelmente

Todavia, como veremos em 6.3., alguns adjetivos em -vel, quando usados com um sentido lexicalizado e/ou quando desprovidos do sentido de potencialidade passiva, como afável, agradável, amável, apreciável, admitem a adjunção de -mente (afavelmente, agradavelmente, amavelmente, apreciavelmente). No seu sentido literal, não se combinam com -mente.

\subsection{Condições de adjunção de -mente}

Além de significar "de modo x", "à maneira de X" (irresponsavelmente 'de modo irresponsável'; pausadamente 'de modo pausado'; "ele reagiu de modo acintoso" (ou acintosamente); «a taxa de juros cresce de modo pouco sustentado" (ou pouco sustentadamente)), os advérbios em -mente também denotam pontos de vista, como em arquiteturalmente/filmicamente falando. Neste caso, como são inúmeros os campos do saber-fazer a que o falante se pode referir, são igualmente numerosos os adjetivos que podem servir de base a advérbios deste tipo (antropologicamente, eolicamente, futebolisticamente, monetariamente, parentalmente, posturalmente).

Os adjetivos de cor não se prestam a uma adverbialização linear no seu sentido literal, por não denotarem 'de modo x' (cf. "pintou a porta amarelamente (?)»; "parede azulmente (?) decorada»; "moradia verdemente (?) requalificada»); em todo o caso, a sua aceitabilidade é marcada por alguma escalaridade, como se observa em "casas brancamente caiadas" (http://diariosdaerrancia. blogspot.pt/2013/02/ 
bencatel.html), "ele era tão roxamente católico» (alusão ao roxo do período da quaresma), "A Disney sempre esteriotipou roxamente o herói, o vilão, a princesa" (http://usinasuburbana.blogspot. pt/2009/04/sipelberg-animaniacs-and-hysteria_11.html). De igual modo, alguns adjetivos de cor são usados adverbialmente em sentido figural, como o atestam os dados extraídos da internet (cf. (29)):

(29) a. amarelamente (cf. "Foto Amor-Amarelamente-Perfeito." Amor-Amarelamente-Perfeito - Olhares.com - Sapo

b. azulmente ("OLX oferece anúncios classificados de azulmente na categoria Áudio» (cf. Azulmente : Classificados de Áudio em Brasil | OLX)

c. castanhamente ("Aqueles olhos castanhos encontraram os meus (castanhamente iguais)" https://naquelaepoca.wordpress. com/2013/05/20/castanhamente-iguais/

d. cinzentamente ( $\mathrm{A}$ paixão de Anna Bolena numa detestável sexta-feira santa cinzentamente portuguesa. Ópera de Viena, Abril de 2011»)cf. https://www.google.pt/search?q=cinzentamente\&ie=utf-8\&oe=utf-8\&gws_rd=cr\&ei=OZH9VLHyIYXvUP74g_gD

e. verdemente (Suíte Umbú: frescor verdemente doce - Casa Mangarosa ... http://casamangarosacanoa.blogspot.pt/p/suite.html

De uma forma geral, os adjetivos que estão na base dos advérbios em -mente podem funcionar como predicadores de actantes, nomeadamente humanos, e de eventos (cf. 30).

(30)

agilmente, alegremente, brandamente, bruscamente, capazmente, dificilmente, dignamente, fielmente, finamente, fortemente, francamente, gravemente, habilmente, honestamente, lentamente, livremente, pobremente, rapidamente, sagazmente, simpaticamente, sinceramente, subtilmente, tristemente, velozmente

Os adjetivos de (30) são maioritariamente simples, no que à sua estrutura morfológica diz respeito. Mas o mesmo se aplicaria a ad- 
jetivos morfologicamente complexos. Este aspeto é particularmente relevante, pois as condições de adjunção de -mente a bases afixadas, sejam prefixadas ou sufixadas, pautam-se mais pela semântica daquelas do que pelo afixo usado. Assim, em geral o advérbio integra composicionalmente o semantismo da base, podendo falar-se em advérbios volitivos, como deliberadamente, intencionalmente, em advérbios partitivos, como parcialmente, em advérbios orientados para o modo (cuidadosamente, suavemente, violentamente), e para todas as demais classes semânticas que caraterizam as bases.

Os adjetivos de significado temporal prestam-se muito à adverbialização através de -mente (anualmente, diariamente). Também neste caso a morfologia interna do adjetivo não assume importância crucial face à semântica do mesmo. Assim, encontram-se advérbios em -mente construídos com base em adjetivos de temporalidade, sejam morfologicamente simples (atual, eterna, nova, súbita), derivados deverbais (atrasada, concomitante, prolongada) ou denominais (episódica, milenar, momentânea, tardia).

\begin{tabular}{|c|c|c|c|}
\hline $\begin{array}{l}\text { atualmente } \\
\text { antecipadamente } \\
\text { anteriormente } \\
\text { antigamente } \\
\text { anualmente } \\
\text { atrasadamente } \\
\text { concomitantemente } \\
\text { contemporaneamente } \\
\text { demoradamente }\end{array}$ & $\begin{array}{l}\text { diariamente } \\
\text { eternamente } \\
\text { frequentemente } \\
\text { futuramente } \\
\text { habitualmente } \\
\text { imediatamente } \\
\text { mensalmente } \\
\text { milenarmente } \\
\text { momentaneamente }\end{array}$ & $\begin{array}{l}\text { novamente 'outra vez' } \\
\text { permanentemente } \\
\text { presentemente } \\
\text { posteriormente } \\
\text { primeiramente } \\
\text { proximamente } \\
\text { prolongadamente } \\
\text { quotidianamente } \\
\text { raramente recentemente }\end{array}$ & $\begin{array}{l}\text { regularmente } \\
\text { seguidamente } \\
\text { semanalmente } \\
\text { semestralmente } \\
\text { subitamente } \\
\text { subsequentemente } \\
\text { temporariamente } \\
\text { ulteriormente } \\
\text { ultimamente }\end{array}$ \\
\hline
\end{tabular}

No que diz respeito à manifestação de grau, são compatíveis com -mente alguns adjetivos na forma superlativa irregular, tais como

(32)maximamente, minimamente, otimamente, pessimamente.

Também as bases adjetivais no superlativo em -íssim- admitem adverbialização em -mente: 
(33) belissimamente, exatatissimamente, inteligentissimamente, lindissimamente

Neste conjunto incluem-se adjetivos de cor, tais como (34-36), atestados em linha, em sítios que usam linguagem informal e/ou figural:

(34) amarelissimamente (http://www.ufsm.br/deusamorna/ ebm5.html),

(35) azulissimamente (www.cinequanon.art.br/gramado_detalhe.php),

(36) vermelhissimamente (belgavista.blogspot.com/2007/08/ vermelho.html)

\subsubsection{Bases prefixadas}

Nos advérbios em -mente construídos com base em palavras já prefixadas, mais do que o prefixo é essencialmente a natureza semântica da base que possibilita, ou não, a adjunção de -mente. No conjunto dos advérbios portadores de prefixos, quanto mais a base já se encontra lexicalizada, quanto mais a base é usada numa aceção não literal e/ou não é já percecionada como composicionalmente prefixada, mais probabilidade há de a adjunção de -mente ser considerada aceitável. Por exemplo, num caso como o de proeminentemente, a interpretação da base proeminente é a equivalente a 'saliente, notável, que sobressai', e é esse o sentido que é herdado pelo advérbio.

Quando o adjetivo denominal que está na base do advérbio remete para um local ou para um topónimo, como em cisalpino, o advérbio em -mente não é bem formado (*cisalpinamente). Já, pelo contrário, quando a base do adjetivo denota temporalidade, a adverbialização em -mente encontra terreno fértil para a sua ativa- 
ção (concomitantemente, pré-nupcialmente, retroativamente). Nos exemplos que se seguem o sinal - representa o espaço em que o advérbio pode ser usado.

(37) ante-: antenupcialmente (acordo celebrado -)

(38) co-: colateralmente

(39) contra-: contraditoriamente

(40) des-: deslealmente, desalmadamente, descaradamente, descartavelmente, desconfiadamente, desconformemente, descontentemente, descontinuadamente, despeitadamente, despudoradamente

(41) extra-: extrajudicialmente, extra-uterinamente (acordo/operação realizado/a -).

(42) hipo-: hipocaloricamente (alimentação - controlada)

(43) in-: impropriamente, inadequadamente, inativamente, inadequadamente, incompletamente, incompreensivelmente, incorretamente, indevidamente, indiferentemente, indiscutivelmente, indistintamente, infelizmente, insensivelmente, insignificantemente, invisualmente, irregularmente, invariavelmente

(44) infra-: infranutridamente

(45) inter-: intercontinentalmente (passeando -)

(46) intra-: intra-arterialmente (alimentado -), intravenosamente

(47) pré-: pré-nupcialmente, pré-contratualmente, pré-prandialmente

(48) pós-/post-: pós-nupcialmente

(49) sobre-: sobrenaturalmente, sobrefaturadamente

(50) sub-: subliminarmente, subconscientemente, subcutaneamente (alimentado)

(51) trans- : transfiguradamente

Os adjetivos temporais, como atual, anterior, antiga, anual, concomitante, contemporânea, diária, episódica, eterna, frequen- 
te, futura, habitual, imediata, mensal, milenar, momentânea, permanente, posterior, prolongada, quotidiana, seguida, semanal, semestral, subsequente, súbita, temporária, raramente admitem negação através de in-, mas quando tal ocorre (inatual, infrequente) a adverbialização não é possível: *inatualmente, *infrequentemente.

Por vezes, na base do advérbio em -mente estão adjetivos prefixados em in- (incansavelmente, inexoravelmente, ininterruptamente) dos quais não existe a forma não prefixada (*cansável, *exorável, *interrupta). Por isso é sempre aquela (incansável, inexorável, ininterrupta) que funciona como base do advérbio. Não obstante, circunstâncias há também em que o adverbializador -mente se combina com bases adjetivas prefixadas em in-e sufixadas em -vel, como inalteravelmente, mas não com as correspondentes bases não prefixadas (*alteravelmente).

\subsubsection{Bases sufixadas}

\subsubsection{Adjetivos deverbais}

$\mathrm{O}$ adverbializador -mente combina-se com adjetivos deverbais portadores de sufixos diversos, como -nte, -dor, -tíci-, -t/siv-, -tóri-, -d-, -vel.

(52)-d-: atrasadamente, consabidamente, aterrorizadamente, perdidamente, (bem/mal) posicionadamente

(53)-diç-: atiradiçamente

(54)-dor: conservadoramente, reparadoramente, tentadoramente

(55)-dour-: duradouramente

(56)-i-: arrediamente, fugidiamente

(57) -nte: abundantemente, ardentemente, brilhantemente, condescendentemente, consistentemente, contundentemen- 
te, delirantemente, desconcertantemente, hesitantemente, deslumbrantemente, estridentemente, exigentemente, florescentemente, fulminantemente, galopantemente, hesitantemente, hilariantemente, intransigentemente, maldizentemente, obedientemente, ofegantemente, penetrantemente, perseverantemente, preferentemente, resistentemente, sorridentemente, sufocantemente, surpreendentemente, terminantemente, titubeantemente, tolerantemente, ululantemente, urgentemente, vibrantemente

(58) -tíci-: ficticiamente

(59) -t/siv-: afirmativamente, administrativamente, agressivamente, cansativamente, informativamente, nutritivamente, pensativamente

(60) -tóri-: contraditoriamente, difamatoriamente, discriminatoriamente

(61) -vel: abominavelmente, aceitavelmente (cf. "instalações aceitavelmente simples"), aconselhavelmente ("A duração dos estágios deve ser acordada entre cada candidato e cada empresa, [...] situando-se aconselhavelmente [...] entre um e três meses" http://www.apecom.pt/biblioteca/boaspraticas/ boas-praticas-materia-aceitacao-estagiarios), admiravelmente, afavelmente, alegavelmente, alteravelmemte, amavelmente ('simpaticamente'), aprazivelmente, desagradavelmente ( $<$ desagradável), desconfortavelmente ('de modo desconfortável'), desprezivelmente (<desprezível).

Dum modo geral, as bases sufixadas em -vel admitem a adverbialização quando (já) desprovidas do sentido de potencialidade passiva (agradavelmente, amavelmente).

Quando há um adjetivo departicipial regular e um irregular, é tendencialmente este o selecionado como base do advérbio (cf. 62). Mas assim não acontece com algumas bases adjetivais departicipiais, 
correspondam elas a formas irregulares (*eleitamente, *supraditamente) ou regulares ("nascidamente, *supramencionadamente).

(62)

\begin{tabular}{l|l|l}
\hline $\begin{array}{l}\text { Adjetivo departicipial } \\
\text { regular }\end{array}$ & $\begin{array}{l}\text { Adjetivo departicipial } \\
\text { irregular }\end{array}$ & Advérbio \\
\hline Atendid- & Atent- & Atentamente \\
Cegad- & Ceg- & Cegamente \\
Completad- & Complet- & Completamente \\
Corrigid- & Corret- & Corretamente \\
Dirigid- & Diret- & Diretamente \\
Fixad- & Fix- & Fixamente \\
\hline
\end{tabular}

\subsubsection{Bases adjetivais denominais}

No âmbito das bases adjetivais denominais (cf. 63-75), mantêm-se válidas as coordenadas semânticas que permitem ou que inviabilizam a combinatória de -mente. Se tomarmos como exemplo os adjetivos sufixados em -al, verificamos que as bases que denotam propriedades relacionadas com tempo ou com espaço são adverbializáveis (anualmente, centralmente, finalmente, inicialmente, lateralmente, ocasionalmente, semestralmente, temporalmente).

(63)-al:

\begin{tabular}{l|l|l|l} 
anualmente & fiscalmente & legalmente & professoralmente \\
artificialmente & formalmente & manualmente & profissionalmente \\
carnalmente & fundamentalmente & marginalmente & regionalmente \\
comercialmente & globalmente & mentalmente & semanalmente \\
criminalmente & grupalmente & normalmente & sexualmente \\
culturalmente & habitualmente & ocasionalmente & tendencialmente \\
espacialmente & individualmente & pessoalmente & tradicionalmente \\
especialmente & industrialmente & policialmente & usualmente \\
essencialmente & instrumentalmente & potencialmente & visceralmente
\end{tabular}

$\mathrm{O}$ mesmo se aplica a adjetivos cujas bases denotam objetos (muralmente falando: cf. https://www.youtube.com/watch?v=UK21g8hbQDc), partes do corpo (arterialmente irrigado, cerebralmente comprometido, facialmente diminuído), estados (gripal), matérias (águas 
mineralmente gasosas), mas também realidades menos tangíveis (naturalmente, potencialmente). Situação idêntica se passa com as bases portadoras dos demais sufixos adjetivalizadores (cf. 64-75).

(64) -an-: anterianamente, balsaquianamente, queirosianamente

(65) -ar: alimentarmente, escolarmente, familiarmente, secularmente

(66) -ári-: arbitrariamente, autoritariamente, diariamente, bumanitariamente, planetariamente, temporariamente, tributariamente, universitariamente ${ }^{67}$.

(67) -eir-: financeiramente, interesseiramente

(68) -esc-: animalescamente, carnavalescamente, cavalheirescamente, dantescamente, folhetinescamente, gigantescamente, livrescamente, principescamente, romanescamente

(69) -ic-: academicamente, antagonicamente, aristocraticamente, atomicamente, automaticamente, ciberneticamente, demagogicamente, democraticamente, energicamente, ironicamente, metalicamente, pacificamente, pateticamente, romanticamente, tipicamente

(70) -il: infantilmente, juvenilmente, mercantilmente, pastorilmente

(71) -ist-: calculistamente, financistamente, saudosistamente

(72) -iv-: altivamente, desportivamente, instintivamente

(73) -onh-: enfadonhamente, medonhamente, risonhamente, tristonhamente

(74) -os-: ambiciosamente, amorosamente, astuciosamente, audaciosamente, corajosamente, criminosamente, deliciosamente, fantasiosamente, gostosamente, harmoniosamente, honrosamente, indecorosamente, maliciosamente, manhosamente, maravilhosamente, milagrosamente, misteriosamente, pompo-

${ }^{67}$ Muitas das palavras portadoras de -ári- são cultismos (comunitariamente, literariamente, monetariamente, paritariamente, solitariamente), não podendo ser interpretadas como construídas no português. Por isso também o seu sentido não é decomposicional, mas encontra-se fortemente lexicalizado. 
samente, perigosamente, preguiçosamente, proveitosamente, religiosamente, substanciosamente, virtuosamente

(75) -ud-: abelhudamente, carrancudamente, telhudamente

Os adjetivos depatronímicos, nomeadamente derivados em -anou em -in-, admitem adjunção de -mente, mormente quando a base denota uma personalidade marcante, como em 'a sociedade foi hitlerianamente fustigada, mesmo após o fim da guerra', ou em 'a cidade foi sendo pombalinamente construída'.

Como muitos adjetivos denominais em -ic- denotam relações especializadas de saber, em conexão com o sentido das bases, os advérbios em -mente prestam-se muito a um uso como advérbios de ponto de vista, como se atesta pelos exemplos seguintes:

(76) agronomicamente, alcoolicamente, arqueologicamente, biologicamente, catastroficamente, cientificamente, economicamente, energeticamente, geograficamente, metodicamente, politicamente, tecnologicamente

\subsection{Sentido das bases}

De uma forma geral, é o sentido não literal ou não composicional, mas o figurado ou o já lexicalizado que é selecionado, como os exemplos (77-78) ilustram.

(77)Amavelmente 'de modo/forma amável', usa amável no sentido de 'simpático, cordial, encantador', e não no sentido literal de 'que pode/merece ser amado'.

(78) Terminantemente equivale a 'categoricamente', usando portanto o valor de 'categórico, decisivo, irrevogável' de terminante, e não o sentido composicional de 'que termina'. 
Casos há, como os seguintes (* denota que a combinação com -mente é agramatical), em que a adverbialização é possível quando é focalizado o sentido não literal, não composicional, mas o lexicalizado.

\begin{tabular}{|l|l|l|}
\hline Base adjetival & 'Sentido literal + -mente & Advérbio em -mente \\
\hline alta & 'de altura elevada' & $\begin{array}{l}\text { altamente 'intensamente': urânio altamente } \\
\text { enriquecido, países altamente endividados }\end{array}$ \\
\hline amarga & 'azeda' (comida) & amargamente 'com amargura interior' \\
\hline cega & 'invisual' & cegamente 'irrefletidamente, sem pensar' \\
\hline dura & 'de dureza elevada' & duramente 'com severidade excessiva' \\
\hline grande & 'de estatura elevada' & grandemente 'sobremaneira, intensamente' \\
\hline larga & 'de largueza acentuada' & largamente 'amplamente' \\
\hline leve & 'de baixo peso' & levemente 'ligeiramente, superficialmente' \\
\hline
\end{tabular}

Quadro VI.1. Sentido (não) literal da base e combinabilidade com-mente

Esta preferência pelo sentido lexicalizado faz-se sentir com quaisquer classes de bases adjetivais com as quais -mente se combina. Trata-se, portanto, de um traço constante deste operador, que importa não negligenciar pelos custos que acarreta em termos de processamento. Em fases precoces de aprendizagem da língua, seja em falantes de português como língua materna, seja em utentes de português como língua segunda e/ou estrangeira, em que o sentido lexicalizado da base não faz ainda parte da competência lexical do falante, este tem de ser memorizado para o advérbio ser usado em conformidade com as convenções comunicativas da língua.

Devido a este comportamento, muitos advérbios em -mente são portadores de valores bem cristalizados, de natureza aspetual (completamente), epistémica (aparentemente, provavelmente), deítica (atualmente), intensiva (absolutamente, altamente, sumamente), não subsumíveis no sentidos composicionais. Os advérbios certamente, efetivamente, obviamente, realmente são usados com valor asseverativo, e possivelmente, provavelmente para exprimir dúvida. 